\title{
Acoustics Australia
}

Acoustics Australia

Editorial Board

Editor-in-Chief:

Marion Burgess (UNSW Canberra, Australia)

Associate Editor:

Danielle Moreau (UNSW Sydney, Australia)

Managing Editor:

Kathryn Latal (Australia)

Editorial Board:

George Dodd

(University of Auckland, New Zealand)

Densil Cabrera

(The University of Sydney, Australia)

Ross Chapman

(University of Victoria, British Columbia,

Canada)

Jer Ming Chen (SUTD, Singapore)

Nicole Kessissoglou (UNSW Sydney, Australia)

Steffen Marburg (Universität der Bundeswehr

München, Germany)

Brett Molesworth (UNSW Sydney, Australia)

Frits van den Berg (Netherlands)

Acoustics Australia is published by the

Australian Acoustical Society

(A.B.N. 28000712 658)

ISSN 0814-6039

Responsibility for the contents of articles and advertisements rests upon the contributors and not the Australian Acoustical Society.

All articles and technical notes (but not

Acoustics Forum and Letters) are sent for peer review before acceptance. Acoustics Australia is abstracted and indexed in all major data bases and has an Impact Factor of 0.630 (2019).

Acoustics Australia

The papers and technical notes are available from the journal website www.springer.com/ engineering/journal/40857.

All members of the Australian Acoustical

Society have free access to the papers and technical notes but must log in via the member area of the AAS website and follow the link to the journal.

Editorial Enquiries

The Editor, Acoustics Australia

AcousticsAustralia@acoustics.asn.au

www.acoustics.org.au

Submissions

All Articles

www.springer.com/engineering/journal/40857

News, New Products

and Books for Review

acousticsaustralia@acoustics.asn.au

Subscription Enquiries www.springer.com/engineering/journal/40857

Advertising

Mrs Leigh Wallbank

Tel (02) 95284362

wallbank.leigh@gmail.com
Vol. 48, No. 3

December 2020

\section{ACOUSTICS NEWS AND REGULAR ITEMS}

Editorials

Abstracts

AAS News \& Division News

Acoustics News

Announcements

Book Review

Future Conferences

Sustaining Members Listing

Diary

\section{GENERAL SUBMISSIONS}

Review Paper

A Conceptual Framework for Acoustic Comfort Classification in Eatery Places: Critical Reviews of the Determining Factors

Noor Aini Mistar, Raha Sulaiman \& Nazli Bin Che Din

Original Papers

Smartphone Sensing and Identification of Shock Noise and Vibration Induced by Gym Activities Sakdirat Kaewunruen \& Chun Lei

Extraction of UAV Sound from a Mixture of Different Sounds

Sana Hikmat Ghani \& Waseem Khan

The Experimental Research of Sound Absorption in Plasters Produced with Perlite Aggregate and Natural Hydraulic Lime Binder

Tarık Serhat Bozkurt \& Sevtap Yılmaz Demirkale

Acoustic Properties of Multilayered Structures

Zhong-Xiang Yuan \& Dong-Xiong

Efficient Acoustic Topology Optimization Using Vibro-Acoustic Coupled Craig-Bampton

Mode Synthesis

Xudong Wang, Deshi Wang \& Bao Liu

Effect of Blade Outlet Angle on Acoustics of Marine Centrifugal Pump

Hongli Zhang, Fanyu Kong, Aixia Zhu, Fei Zhao \& Zhenfa Xu

A Study on Active Noise Reduction of Automobile Engine Compartment Based on Adaptive

LMS Algorithm

Congbing Wu \& Ping Yu

Study on Aerodynamic Noise Numerical Simulation and Characteristics of Safety Valve Based on Dipole and Quadrupole

Shuxun Li, Jianjun Hou, Weiliang Pan, Zhihui Wang \& Yunxing Kang

Sound Source Localization Using Piezoelectric Acoustic Metasurfaces

Jin-Cheng Gu, Wei Lin \& Cai-Xia Kan

Head-Related Transfer Function Personalization Based on Modified Sparse Representation with Matching in a Database of Chinese Pilots

Dongdong Lu, Xiangyang Zeng, Xiaochao Guo \& Haitao Wang

Technical Notes

Effect of a Transducer Horizontality Default on Lake Fish Stock Assessment

Arthur Blanluet, Chloe Goulon, Anne Lebourges-Dhaussy, Pauline Eymar-Dauphin \& Jean Guillard 


\section{FROM THE PRESIDENT}

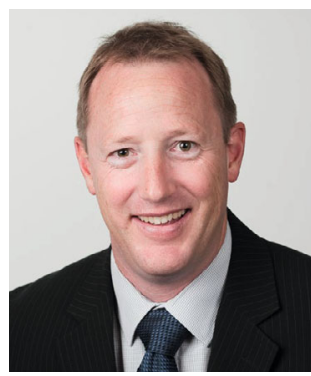

\section{MESSAGE FROM THE OUTGOING PRESIDENT}

As my two years of service as President of the Australian Acoustical Society comes to an end, this will be my final message from the President. I would like to take this opportunity to thank the Federal councillors and General Secretary for their support and encouragement during my term, it has certainly made the role much more enjoyable and easier than I had anticipated.

I'm proud of what the AAS has achieved when I reflect back on the past two years. We have introduced live streaming capability of our technical presentations, which has certainly proved to be a valuable capability when the Covid pandemic hit us earlier this year. We have set up a new and improved website, thanks to a lot of hard work by our web master, Luke Zoontjens, and General Secretary, Julie Sobolewski. We have prepared a framework for a Continuing Professional Development program and we are currently in the process of preparing a Constitution to replace our aging Memoranda, with updates to the By Laws and Code of Ethics, which should make implementation of the CPD program much more streamlined when the time comes. With much hard work by our General Secretary, we have also digitised almost all of our past Conference Proceedings -it is noted that the AAS did not have copies of all proceedings so I would like to thank those that lent a copy of their past proceedings to aid the digitisation process.

Unfortunately, the Covid pandemic has also meant the postponement of two of our annual conferences, with our Joint Meeting with the New Zealand Acoustical Society postponed to November 2022, and the Joint Meeting with the Acoustical Society of America, WESPAC and PRUAC postponed to December 2023. Watch this space for 2021 as the AAS plans to resume our face-to-face annual conferences and get back to normal operations (safely and in accordance with all state and federal requirements) as soon as possible.

Simon Moore, President, AAS

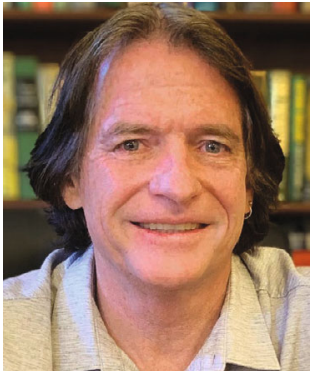

\section{MESSAGE FROM THE INCOMING PRESIDENT}

As the incoming President, I'd like to firstly take the opportunity to thank Simon for his leadership, particularly over the recent difficult period. He has worked diligently with our General Secretary, Julie and Treasurer, Michael to bring the Society up to proper and efficient business standards that is serving us well in our ability to function and grow. Secondly, I need to acknowledge how fortunate I am to have Simon to support me in this transition period. The Society faces challenges in the 'new normal' world, and it will be the Federal Council's role to steer a safe course whilst being adaptive to our member's needs. As you would already be aware, travel restrictions have played havoc with conferences. For the first time in decades we will not host an annual conference, our joint meeting with the Acoustical Society of America scheduled for next year has now been postponed until 2023, whilst our joint conference with our friends across the 'ditch' in Wellington is rescheduled until 2022. We are busily looking at all options for 2021 and would hope to confirm something in the very near future, so ask that you all start thinking of an abstract to submit. In the meantime, the State Divisions are doing their part by continuing the excellent on-line Tech Talks.

Finally, I would like to say that I am humbled by the opportunity to serve you over the next two years.

Jeff Parnell, President Elect

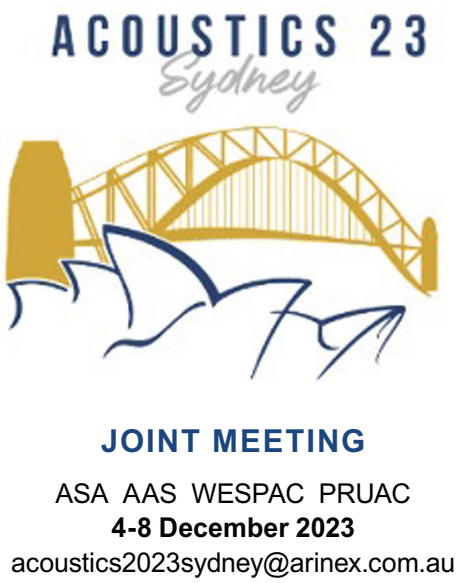




\section{FROM THE CHIEF EDITOR}

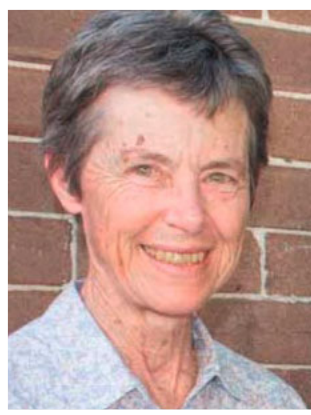

This issue of the journal comprises 12 papers on a diverse range of topics. The review paper discusses the range of acoustic qualities for eateries and the need to balance of control of reverberation with the expectation of the character of the eatery. Some years ago, the Acoustical Society of New Zealand introduced the CRAI as a "Café and Restaurant Acoustical Index" as a rating system for eating venues. The AAS also included this on their website at that time. Perhaps this manuscript will be a stimulus to revive some promotion of this index in 2021 as we hope Australians continue to move out of the 2020 Covid 19 restrictions and return to socialising in larger numbers in these social venues.

The ten papers and one technical note demonstrate the range of topics that are encompassed by the term acoustics. The outcomes of the research studies on aspects like effect of blade angle on a pump and localization of a sound using metasurfaces, along with the theoretical optimization studies may well lead to development of instruments and web tools that become available to practitioners in the not too distant future. In parallel the technical note on effect of positioning of an underwater transducer is applicable to those currently undertaking such investigations.

We continue to receive many manuscripts and thus far in 2020 have received 155 and anticipate by the end of the year will be close to 200 . However, we still receive only a very small number from researchers and practitioners in Australia. We encourage more AAS members to consider Acoustics Australia especially as we have now achieved a Q2 ranking. The review articles, original manuscripts and technical notes are submitted via the Editorial Manager system, go through the peer review process and if accepted are fully citable with their own unique identifier (DOI). Forum articles are published within this front section, dealt with locally with an internal review process similar to that for a conference paper. While Forum articles do not have a $\mathrm{DOI}$ they can be referenced in reports as they are traceable and published with the open access News and Notes on the Springer site for each issue of the journal. Thus the findings are shared with colleagues in a similar way to a conference paper. As there has been no annual conference this year we suggest that the journal offers the opportunity for you to prepare a technical note or forum article on the topic that you would have shared with colleagues at a gathering.

As the number of submissions have grown, it has been wonderful to have someone as competent as Danielle Moreau as an Associate Editor. Every manuscript that arrives at the Chief Editor desk has to be read before a decision is made to proceed to the next step for review. Once that decision is made, the challenge is to select appropriate reviewers and then deal with the responses. Danielle has learnt the system quickly and has shared the load. I have full confidence that she will do an excellent job when she takes over as Chief Editor in 2021 and I become an Associate Editor. It is important to have a transition plan for the future so we welcome anyone who has an interest in editing and would like to join as an additional Associate Editor for the journal to contact us.

Marion Burgess, Editor-in-Chief

\section{AUSTRALIAN ACOUSTICAL SOCIETY ENQUIRIES}

\section{NATIONAL MATTERS}

* Notification of change of address

* Payment of annual subscription

Julie Sobolewski - General Secretary Australian Acoustical Society PO Box 1843 Toowong DC QLD 4066 Tel: 0431970049

gs@acoustics.org.au

www.acoustics.org.au

\section{AAS MEMBERSHIP}

For 2019/20 Financial Year (Inc. GST):

Fellow and Member $\ldots \ldots \ldots \ldots \ldots \ldots \$ 160$

Graduates ................. \$122 - \$160

Associate and Subscriber........... \$122

Retired and Maternity. . . . . . . . . . . . \$48

Students and retired fellows .........No Charge
DIVISIONAL MATTERS

Enquiries regarding membership and sustaining membership should be directed to the appropriate State Division Secretary
AAS - NSW Division

\section{Laura Keen}

Tel: (02) 89340035

laura.jane.keen@gmail.com

Richard Devereux

Tel: (07) 32170055

rdevereux@acran.com.au
AAS - QLD Division

\section{AAS - SA Division \\ Adam Cook}

Tel: (08) 71006400

adam.cook@aecom.com

AAS - VIC Division

Dr Marc Buret

Tel: (03) 84582671

vic-secretary@acoustics.asn.au
AAS - WA Division

Benjamin Farrell

Tel: (08) 94745966 ben@gabriels.net.au

www.acoustics.org.au 


\section{ACOUSTICS AUSTRALIA 48(3), 2020 ABSTRACTS}

The full papers for these abstracts can be found in the online version of Acoustics Australia. Members of the Australian Acoustical Society should access via the member login on the AAS website. Access for all others is via:- http://link.springer.com/iournal/40857

\section{GENERAL SUBMISSIONS REVIEW PAPER}

\section{A Conceptual Framework for Acoustic Comfort Classification in Eatery Places: Critical Reviews of the Determining Factors}

Noor Aini Mistar ${ }^{1}$, Raha Sulaiman ${ }^{1}$ \& Nazli Bin Che Din ${ }^{1}$

1. The Centre for Building, Construction and Tropical Architecture (BuCTA), Faculty of Built Environment, University of Malaya, Kuala Lumpur, 50603, Malaysia

In the context of eatery places, it is important that people concentrate and focus on the smells and tastes of their food and drinks to ensure that they are satisfied with their meals, as this influences the positive behavior of the intent to return and can prompt them to recommend an eatery place to others later. A higher level of noise may distract people from having a fine dining experience and could interfere with their sense of smell and taste. Ultimately, long-term exposure to noise will affect not only a person's health and well-being but also his or her social interactions, communication and preferences for acoustic comfort during the dining experience. This paper will discuss the critical literature reviews of the determining factors of this phenomenon in order to develop a conceptual framework by which to classify eatery place typologies and diners' perceived acoustic comfort. The main goal of this paper is to clearly elucidate the different categorizations of eatery places and the determining factors that might have significant effects on human acoustic comfort. Therefore, the paper aims to develop a framework based on the determining factors of acoustic comfort classification in eatery places. This framework can be used by diners as a reference for selecting suitable eatery places based on their preferences.

\section{ORIGINAL PAPERS}

\section{Smartphone Sensing and Identification of Shock} Noise and Vibration Induced by Gym Activities

Sakdirat Kaewunruen ${ }^{1}$ \& Chun Lei $^{2}$

1. Department of Civil Engineering, School of Engineering, University of Birmingham, Birmingham, B152TT, UK

2. Department of Civil and Environmental Engineering, Imperial College London, South Kensington, London, SW7 2AZ, UK

Fitness culture has significantly grown since the nineteenth century. In the recent decade, the gym and fitness industry have thrived in many countries. The construction of gymnasiums has increased dramatically, and fitness centres have become one of the most common spaces in mix-used buildings around the world. There are a significant number of gyms located relatively close to residential areas, some of which have even proposed to operate $24 \mathrm{~h}$ a day. The noise and vibration generated by dropping free weights in the gym affect the user experience and the surrounding community to a certain extent. In addition, today's gyms are frequently operated out of refurbished retail units. Most refurbished unit buildings' structures were never designed to host a gym, which makes the mitigation of noise and vibration very difficult. Based on critical literature reviews, the use of gymnasiums flooring system is relatively straightforward to mitigate the noise and vibration, but its effectiveness is hardly monitored. This study mainly discusses the use of material for mitigating noise and vibration in the gymnasiums together with the crowd sensing evaluation of vibration effectiveness, uncertainty and material deterioration to manage appropriate level of noise and vibration. The gym at the University of Birmingham has been chosen as a case study. Over $10 \mathrm{~h}$ of field tests have been conducted to record data of the operating floor material in the gym and fitness centre using novel smartphone sensors. Considering the specific floor material, a strategy of reducing noise and vibration is proposed. In addition, health and safety assessments are also carried out to evaluate the public safety condition in the gym. The insight into novel crowdsourcing smartphone sensors can help end-users to monitor the environmental impacts around the gyms and surroundings in real time.

\section{Extraction of UAV Sound from a Mixture of Different Sounds}

Sana Hikmat Ghani ${ }^{1} \&$ Waseem Khan ${ }^{2}$

1. Department of Avionics Engineering, Air University, Islamabad, Islamic Republic of Pakistan

2. Department of Electrical Engineering, Air University, Islamabad, Islamic Republic of Pakistan

With the rapid advancement of technology of unmanned aerial vehicles (UAVs), security and safety of military and civil infrastructure have been jeopardized. By exploiting the unreliable capabilities of radar to detect low-flying UAVs with small radar cross section, they can be utilized for malicious purposes, e.g., unauthorized surveillance. To detect UAVs, therefore, various other techniques including audio sniffing/analysis of environment have been investigated. It has been shown recently that a UAV can be differentiated from other sound generating objects based on the various features extracted from the sound captured by a single or multiple acoustic sensors. However, features extraction and classification process can only give reliable results if it is fed with a sound generated by a single source. In practice, the captured sound may be a mixture of contribution of two or more different sources. In this paper, we investigate a wellknown blind source separation technique, known as projection pursuit, to separate the constituent sounds in a mixture. We have considered a scenario when the different mixed unvoiced sounds are independent and non-Gaussian. The results show that in the given scenario, projection pursuit can be applied successfully to separate UAV sounds from various other unvoiced sounds. 
The Experimental Research of Sound Absorption in Plasters Produced with Perlite Aggregate and Natural Hydraulic Lime Binder

Tarık Serhat Bozkurt ${ }^{1}$ \& Sevtap Yılmaz Demirkale ${ }^{1}$

1. Department of Architecture, Istanbul Technical University, Istanbul, Turkey

Restoration of historical buildings should be carried out without giving damage to the existing historical building, and material selections should be determined in accordance with the historical building structure. In addition to the selection of materials compatible with the historical structure, the selection of materials that can improve the interior acoustic quality of the space is one of the important parameters. In this research, increasing the sound absorption coefficient in the plaster layer was investigated to enhance the acoustic quality of historical places. Accordingly, plaster layers prepared with a natural hydraulic lime binder, which are frequently used in restorations, were examined in this research. It was aimed to increase the sound absorption coefficient by making some content changes in the mortar mixture used in the plaster layer. Within the scope of the research, the effects of the lightweight aggregate type used in the plaster layer on the sound absorption coefficient were investigated. The use of flax fiber and polypropylene fiber additive in the plaster layer produced with perlite aggregate was researched, and its effects on the sound absorption coefficient were detailed. Also, the utilization of crumb rubber instead of perlite aggregate was examined, and its effect on the sound absorption coefficient was investigated. In this study, besides sound absorption coefficient tests, compressive strength, flexural strength, open porosity, and capillary water absorption tests were performed. It was determined that the use of lightweight aggregate type can positively affect the sound absorption coefficient. It was identified that polypropylene fiber additives can increase sound absorption at high frequencies and flax fiber additives can increase sound absorption not only at high frequencies but also at low frequencies. It was observed that the use of crumb rubber additives can significantly increase sound absorption at low frequencies and it can enhance sound absorption at high frequencies. As a result, systematic research was performed to increase the sound absorption coefficient in the plaster layer.

\section{Acoustic Properties of Multilayered Structures}

Zhong-Xiang Yuan ${ }^{1}$ \& Dong-Xiong ${ }^{2}$

1. School of Mechanical and Automotive Engineering, South China University of Technology, Guangzhou, 510640, People's Republic of China

2. Ningbo Tuopu Group Co., Ltd., Ningbo, 315800, People's Republic of China

The acoustic performance of multilayered structures (MLSs) can be identified by experiments and calculation models that use commercially available software. This paper presents both an experimental method and data processing techniques that can be used for obtaining the acoustic characteristics of MLSs. During the described experiments, three types of MLSs with different structures are designed and manufactured, and their acoustic characteristics are investigated. In addition, the porosity, flow resistivity, tortuosity, and characteristic lengths of materials are determined experimentally and by using the calculation model. A calculation model for the acoustic performance of an MLS is proposed, and the calculated absorption coefficient and insertion loss derived are compared favorably with the results of experimental data, which validates the proposed models. The analytical methods and conclusions are useful in the design and the tuning of the MLSs.

\section{Efficient Acoustic Topology Optimization Using Vibro-Acoustic Coupled Craig-Bampton Mode Synthesis}

Xudong Wang ${ }^{1}$, Deshi Wang ${ }^{1}$ \& Bao Liu

1. College of Weaponry Engineering, Naval University of Engineering, Wuhan, 430033, Hubei, People's Republic of China

2. College of Electronic Engineering, Naval University of Engineering, Wuhan, 430033, Hubei, People's Republic of China

Continuum topology optimization is an effective way to reduce vibration and noise of vibro-acoustic coupling system. However, the high computation time required for calculating the vibro-acoustic responses during topology optimization is a major obstacle for practical applications. In this paper, a novel symmetric method of vibro-acoustic system matrix is proposed, and a new model reduction method is developed based on Craig-Bampton mode synthesis method to compute dynamic responses with adequate efficiency and accuracy for topology optimization. The comparison results show that the proposed method substantially reduces the degrees of freedom (DOFs) and calculation time. The response values and eigenfrequencies calculated by the model reduction method are exactly the same as those of the full model. Furthermore, the bidirectional evolutionary structural optimization (BESO) algorithm is applied to solve the problem of minimizing the response of a single frequency and a certain range of frequency excitation at a specified target point. The results show that the optimization algorithm converges fast, the iterative process is robust and the response values of different coupling systems can be reduced to a higher extend, which indicates the applicability of the optimization algorithm.

\section{Effect of Blade Outlet Angle on Acoustics of Marine Centrifugal Pump}

Hongli Zhang ${ }^{1}$, Fanyu Kong ${ }^{1}$, Aixia Zhu ${ }^{2}$, Fei Zhao ${ }^{1,3}$ \& Zhenfa Xu ${ }^{1}$

1. Research Center of Fluid Machinery Engineering and Technology, Jiangsu University, Zhenjiang, 212013, China

2. Shanghai Ruizhen Automation Technology Co., LTD, Shanghai, 201306, China

3. School of Mechanical Technology, Wuxi Institute of Technology, Wuxi, 214121, China

To research the effect of blade outlet angle on acoustics of marine centrifugal pump, the unsteady numerical simulation analysis of the four models is carried out and the dipole source of pump shell is extracted. The constraint modal of pump, interior sound pressure level (SPL), exterior acoustic directivity and sound power level are obtained. The results show that five and six SPL peaks appear at BPF and blade frequency multiplier in the pump inlet and outlet, respectively, the SPL peak value is the largest at blade passing frequency (BPF), and the interior acoustics propagates to inlet and outlet directions, and to outlet more significantly. The exterior acoustic directivity in the four models is the same in all directions, and the blade outlet angle has little influence on the changes of exterior acoustic directivity. The SPL at BPF and 2BPF in $Y=0$ plane is significantly smaller than that in $X=0$ and $Z=0$ planes, and the difference of maximum SPL at BPF is $7.2 \mathrm{~dB}$ and $8.0 \mathrm{~dB}$ and that at $2 \mathrm{BPF}$ is $7.6 \mathrm{~dB}$ and $6.4 \mathrm{~dB}$, respectively. The sound power level is maximum at $2 \mathrm{BPF}$, and that at the BPF and 2BPF increases first and then decreases with the blade outlet angle increases. When 
the blade outlet angle is $40 \mathrm{o}$, the interior and exterior acoustic performances are better. The experimental value of the SPL in model 35 is basically consistent with the simulated value, which fully indicates that the numerical simulation analysis has high accuracy and provides support for the credibility of the acoustic simulation results.

\section{A Study on Active Noise Reduction of Automobile Engine Compartment Based on Adaptive LMS Algorithm \\ Congbing $\mathrm{Wu}^{1}$ \& Ping $\mathrm{Yu}^{1}$ \\ 1. School of Electrical and Optical Engineering, West Anhui University, Lu'an, 237012, Anhui, China}

The engine compartment is the main source of automobile noise. In this paper, based on the study of the noise characteristics of the engine compartment, the relationship model is established between engine speed and noise frequency, and an active noise reduction method is proposed based on the adaptive least mean square (LMS) algorithm. Because the adaptive change of the convergence factor is controlled by noise error, the method can reduce the steady-state error of the algorithm and improve the convergence speed of the algorithm. Through the analysis of single-channel active noise reduction control method, we deduced that this method can also realize multichannel and multi-frequency point active noise reduction. Simulation and experimental results show that the convergence rate and steady-state error of the adaptive LMS algorithm are both taken into account in our method; the two-channel noise reduction experiment also shows that the total sound pressure level of channel one and channel two is reduced by 4.6 and 9.6 $\mathrm{dB}$, respectively, which fully shows the feasibility of the multichannel active noise reduction method based on the adaptive LMS algorithm.

\section{Study on Aerodynamic Noise Numerical Simulation and Characteristics of Safety Valve Based on Dipole and Quadrupole}

Shuxun $\mathrm{Li}^{1}{ }^{1}, 2$, Jianjun $\mathrm{Hou}^{1}, 2$, Weiliang $\mathrm{Pan}^{1},{ }^{2}$, Zhihui Wang ${ }^{1},{ }^{2}$ \& Yunxing Kang ${ }^{1}, 2$

1. Lanzhou University of Technology, Lanzhou, 730050, China

2. Machinery Industry Pump Special Valve Engineering Research Center, Lanzhou, 730050, China

Aiming at the problem that it is difficult to accurately predict the aerodynamic noise in the safety valve exhaust process, a new numerical simulation method that comprehensively considers the dipole sources and the quadrupole sources is proposed. The RNG $k-\oplus$ model is used to simulate the steadystate flow fields, LES numerical method is used to simulate the transient flow, and then the unsteady disturbances are used as source terms in the generalized FW-H solver incorporating the dipole and quadrupole terms to solve for the acoustic field. This simulation method is used to calculate the exhaust noise of the safety valve under six different operating conditions, the sound source characteristics of the exhaust noise of the safety valve are analyzed, and the safety valve exhaust test of different working conditions was carried out. The results show that the relative errors of total sound pressure level between simulation and test does not exceed $5 \%$ under different exhaust pressures and different opening heights of the safety valve flap. By comparing the total sound pressure level logarithmically superimposed with the total sound pressure level of the dipole and the quadrupole, the sound source characteristics of the aerodynamic noise of the safety valve are mainly dominated by the sound source of the quadrupole. As the opening height of the safety valve flap and exhaust pressure increase, the total sound pressure level of the safety valve exhaust noise increases, while the relative errors between the simulation results and test data decrease. The proposed simulation method can be accurately applied to the prediction of the safety valve exhaust noise, and the prediction accuracy of this simulation method also increases when the opening height of the safety valve flap and exhaust pressure increase.

\section{Sound Source Localization Using Piezoelectric Acoustic Metasurfaces}

Jin-Cheng Gu${ }^{1}$, Wei Lin ${ }^{1}$ \& Cai-Xia Kan ${ }^{1}$

1. College of Science, Nanjing University of Aeronautics and Astronautics, Nanjing, 211100, China

Nowadays, the sound source localization is widely applied in various fields, with a focus on arrays or algorithms. Meanwhile, acoustic metasurfaces have recently attracted enormous interest in material science. This paper proposed a kind of piezoelectric acoustic metasurface, whose structure is theoretically proved to be useful in sound field orientation or sound source localization. The metasurfaces consist of forty units made up of a resonancelike cavity and a piezoelectric composite sheet in air. By scanning through space and frequency, it has been investigated that the effective interval can reach $30^{\circ} \leq \theta \leq 150^{\circ}$-and $-200 \leq x \leq 200 \mathrm{~cm}$ under far-field and near-field scenario, respectively. Meanwhile, the bandwidth of the structure was evaluated to be up to 800 $900 \mathrm{~Hz}$ in both scenarios. In addition, this paper analyzed three factors affecting the interval: frequency, the size of the metasurface, and the number of elements. The results of this paper has opened up a new way for sound source localization and metasurfaces.

\section{Head-Related Transfer Function Personalization Based on Modified Sparse Representation with Matching in a Database of Chinese Pilots}

Dongdong $\mathrm{Lu}^{1}$, Xiangyang Zeng ${ }^{1}$, Xiaochao Guo ${ }^{2}$ \& Haitao Wang ${ }^{1}$

1. Northwest Polytechnical University, No. 127 Youyixi Road, Beilin District, Xi'an, 710072, Shaanxi, People's Republic of China

2. Air Force Medical Center of FMMU, Beijing, 100142, People's Republic of China

A new method of head-related transfer function (HRTF) personalization was built to optimize new user matching in the HRTF database to enhance 3D virtual hearing. The method of modified sparse representation (MSR) treated the HRTF personalization for an incomer as the task of finding similar subjects in the HRTF database with sparse representation (SR) of the incomer's anthropometric features under the assumption that the equivalent sparse combination expresses the same anthropometric features and HRTFs for virtual hearing. The correlations among principal component coefficients and all anthropometric parameters were calculated after principal component analysis of the HRTF database for the same orientation. A derived database of anthropometric parameters was reconstructed, and SR was performed for all subjects in the original HRTF database. When the SR of the incomer was best matched with that of a subject in the derived database, the HRTF of the matched subject was used for the incomer's 3D virtual hearing. The effect of MSR HRTF personalization was evaluated by spectral distortion. The results showed that the proposed 
method performed better than the others with the Chinese pilots database and the CIPIC database, especially in the frequency range of $0-8 \mathrm{kHz}$.

\section{TECHNICAL NOTES}

\section{Effect of a Transducer Horizontality Default on Lake Fish Stock Assessment}

Arthur Blanluet ${ }^{1}$, Chloe Goulon ${ }^{1}$, Anne Lebourges-Dhaussy ${ }^{2}$, Pauline Eymar-Dauphin ${ }^{1}$ \& Jean Guillard ${ }^{1}$

1. CARRTEL, INRAE, Univ. Savoie Mont Blanc, 74200, Thonon-lesBains, France

2. LEMAR, IRD, UBO, CNRS, Ifremer, 29280, Plouzane, France

Freshwater hydroacoustic surveys are frequently performed with small research boats. Thus, the transducer, usually fixed on a pole on the side of the boat, could be misaligned with the horizontal axis (i.e., the lake surface). Given that fish acoustic responses are strongly directional, the transducer angle could induce attenuation of their backscattering strengths. To test the influence of a small shift of the transducer orientation, we compared hydroacoustics estimates from two sampling nights on the Lake Annecy: the first one being a transducer angle of $1.5^{\circ}$ with the horizontal and the second one being strictly horizontal. We showed that the effect of such an angle is negligible over the sampling variability on the TS distribution of the fish population and the biomass assessment. We conclude that a small shift in the transducer horizontality $\left(\leq 1.5^{\circ} \leq 1.5^{\circ}\right)$ will not degrade the quality of the acoustic data.

\section{Matrix Resilient Wall Ties and Floor Mounts}

The Matrix range of resilient acoustic wall ties and floor mounts are a structural connection that reduces airborne and impact noise passing through masonry and stud walls. They are suitable when discontinuous construction is required in separating walls and any specialised room that requires high acoustic isolation.

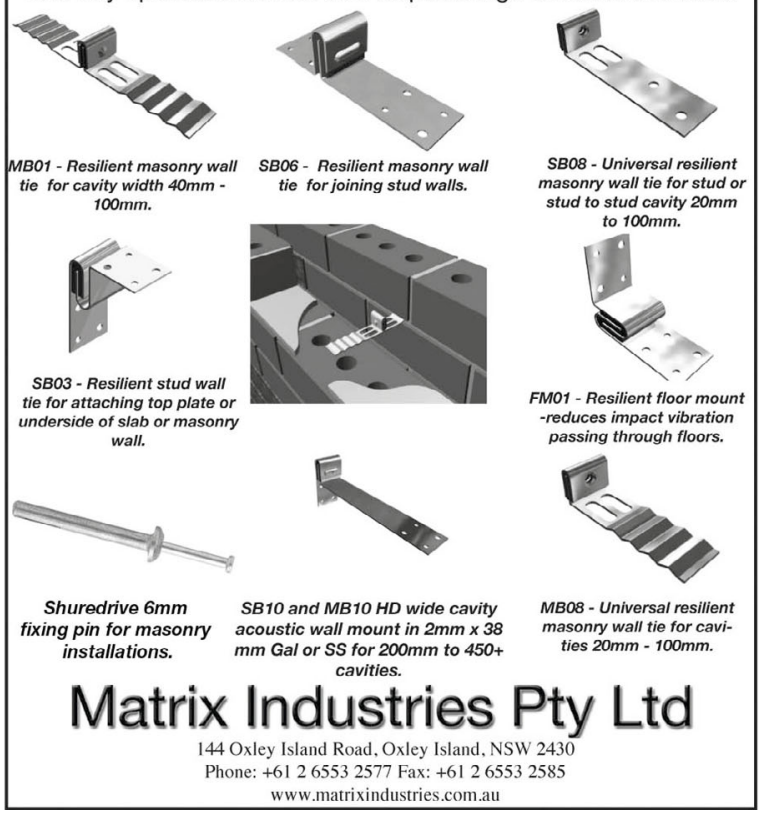

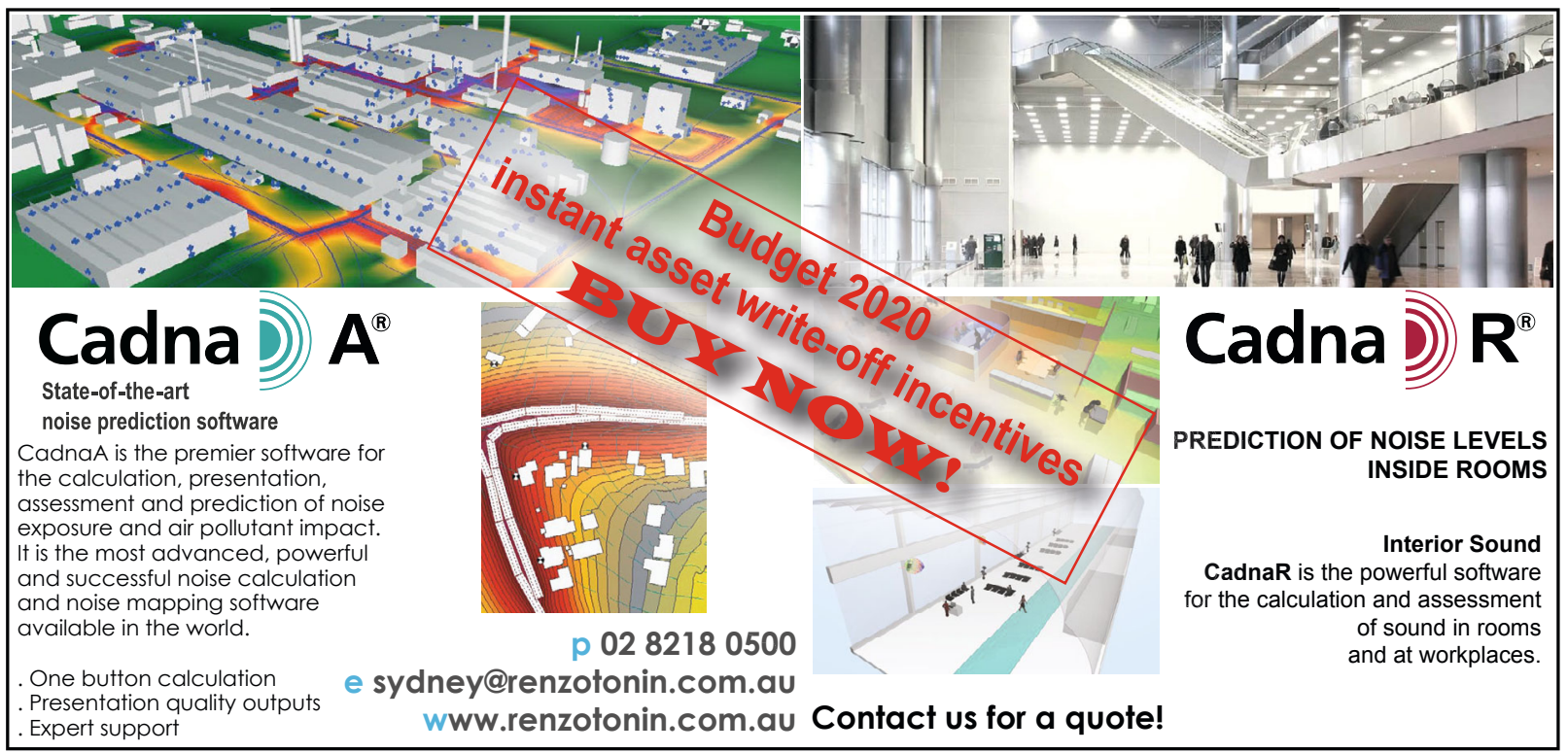

Acoustics Australia Vol. 48, No. 3, December 2020 


\title{
New instrument from Svantek SV 973 Class 2 Sound Level Meter
}

14. Acu-Vib Electronics

\author{
S) SVANTEK \\ sound and vibration
}

Acu-Vib Electronics is the only partner in Australia and New Zealand that in-house calibrate, sell and rent out SVANTEK's leading instruments in this field.

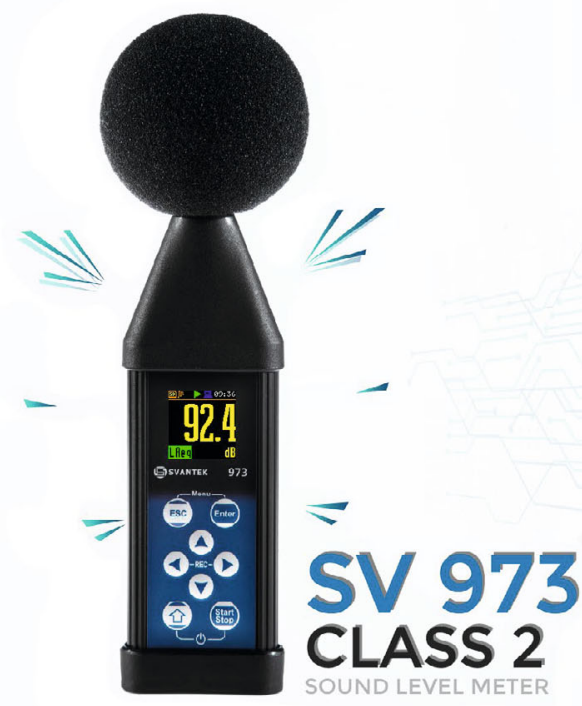

- SV 973 Sound Level Meter is CLASS 2 instrument in accordance to IEC 61672-1:2013

- Microphone in MEMS technology with lifetime warranty

- Sound exposure meter mode with measurement range up to $141 \mathrm{~dB}$

- Wide frequency range up to $10 \mathrm{kHz}$

- Automatic calibration

- OLED display

- Noise sources recognition with $1 / 1$ and 1/3 octave and audio recording

- RT60 reverberation time measurement in $1 / 1$ or 1/3-octave bands in accordance to ISO 3382

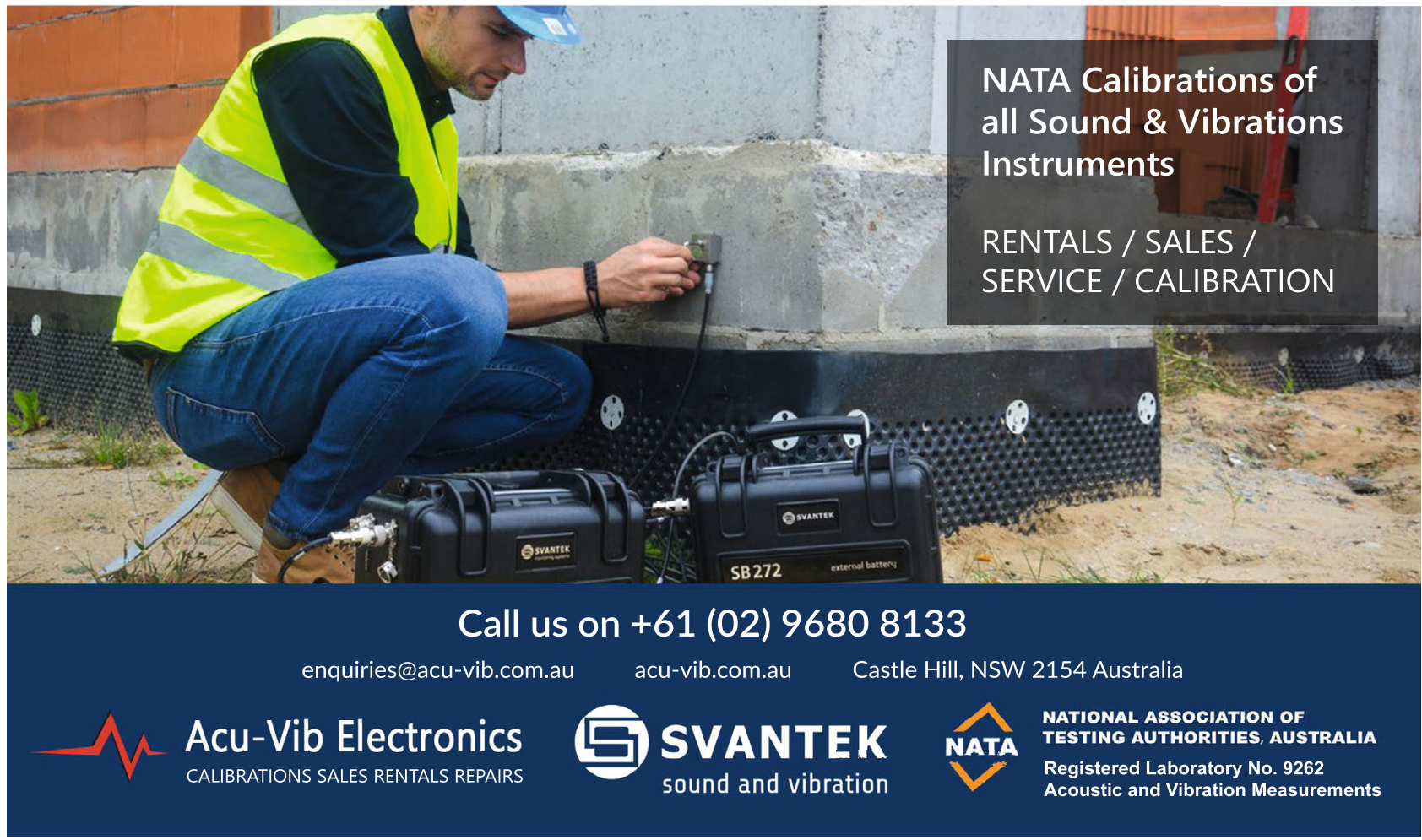




\section{AAS News}

\section{From the General Secretary}

It has been an interesting and challenging year for the Society and members. The COVID-19 pandemic has enabled and forced many changes to the way we all work. The AAS has met the challenges posed by the pandemic and has emerged successfully from the COVID cocoon better equipped to deal with modern times, more technologically savvy and with excellent member retention.

As I write this report AAS membership numbers stand at 704 across all the State Divisions including pending applications and Sustaining members.

The Federal Council has met frequently over the last year and a number of matters have been tabled. COVID- 19 has impacted the way we all do business and the AAS has had to re-evaluate how it operates. Provisions to accommodate the imposed restrictions and potential future restrictions/changes have been considered and implemented. With the wealth of knowledge, history and experience the Federal Councillors have this has been a thorough and well executed process. As a result, the Society is well placed to deal with the ever-changing times and will hold strong in the future.

The new website has posed a few challenges, however most operational procedures now flow without issue. Some fine tuning is still occurring, and will no doubt continue as we all find our feet with the new software. I would like to thank all the members that have notified me of the issues they have experienced, providing an opportunity for these to be resolved as quickly and efficiently as possible. I would also like to thank the State Divisions for their patience and perseverance in utilising the new interface. As we drift out of 2020 and into 2021, the AAS hopes to present new features to members via the website at www.acoustics.org.au

The AAS has been quietly endeavouring to reduce the ecological footprint of Society. The Federal Council approved a motion to 'go digital' as much as possible at last year's meeting in Cape Schanck. The transition has occurred gradually over the last year and currently the only paper documentation produced by the AAS is in the form of membership certificates. All AAS membership certificates and accompanying documentation are now created using recycled and/or environmentally sustainable paper products. All AAS paper waste is securely crosscut shredded to level P4 and recycled locally. AAS paper waste has contributed to local worm farms, gardens and compost bins minimising the impact the AAS has on the planet in this regard and helping to grow the future!

As I enter my third year working with you all I continue to enjoy the experience. I have learnt a lot, met some fascinating people, and gained new skills. I look forward to assisting members and supporting the Society as it continues to grow over the next year.

Finally, I wish all members, affiliates, and supporters of the AAS a safe, healthy and happy Christmas and New Year. See you all in 2021!

Julie Sobolewski

\section{NSW Division}

The NSW Division was able to a hold another successful technical talk via Zoom in October attracting up to 68 members, not only from NSW but from a range of states. The presentation was by Simon Kean (Director, Spoke Acoustics Pty Ltd) who spoke on the Glebe Island and White Bay Draft Port Noise Policy which has been developed for the Port Authority of NSW.

The presentation provided the background and reasoning behind the development of the new noise policy for managing a range of port noise issues. The reasoning and methodologies the proposed approaches for managing vessel noise and cumulative noise impacts from noise generating port operations for existing and future tenants was discussed. The presentation lead to a range of interesting follow up questions from members exploring how the policy would work in practice and where the approach may lead.

Due to the current circumstances, this year's AAS/ASNZ conference due to be held in Wellington has been postponed until 2022 and so there will be no conference held in 2020. NSW is currently looking at options to fill in for the postponed joint meeting with the Acoustical Society of America in 2021 with Wollongong firming up as the current favourite. More details will be released soon, but in the meantime, start working on an abstract or two.

Angus Leslie

\section{WA Division}

The WA Division held its AGM and a networking lunch on October 29, 2020. The event was held at The Melbourne in the Perth CBD. The lunch was a fantastic opportunity for members to catch-up after what has been a challenging year due to the COVID-19 pandemic.

The WA Division will be holding its annual Christmas dinner at The Island at Elizabeth Quay on December 4, 2020. Members are requested to view the event details and to register in the Events section of the AAS website.

Benjamin Farrell

\section{VIC Division}

The Division activities have resumed via videoconferencing, with a first technical talk by Derek Thompson from WSP on the commissioning of a public address system for a road tunnel in New Zealand on 11 August. The Division held its annual general meeting on 1 September. Current committee members were all willing to stand again and were re-elected. Amanda Robinson joined the committee. Following the meeting, Peter Pirozek from USG Boral Building Products Pty Ltd presented on the effects of mass-air-mass resonance on the $\mathrm{Rw}+\mathrm{Ctr}$ performance of wall systems.

Another technical meeting was scheduled on 27 October 2020 with Dr Jordan Lacey, from RMIT University presenting on sound installation prototypes for enhancing the quality of human life in public urban spaces.

Mid-August, the Division initiated the coordination of a noise monitoring project, aiming at collecting noise level data measured during the lock-down in place in response to the pandemic; and again for comparison, once restrictions have 
been lifted. Members have volunteered to conduct noise measurements at locations they have access to while abiding with the restrictions in place. Over twenty sites were identified across metropolitan Melbourne. Data from the first round of measurements are currently under review and analysis. The second tier of this project is yet to be scheduled. The outcome of the project will depend on the quality of the data, and more information will be provided in due course.

Early October, the Victorian Government concluded the first of two rounds of public consultation on the implementation of the Professional Engineers Registration Act 2019 (for more details see https://engage.vic.gov.au/engineers-registration). In response to concerns raised by some members, the Division made a submission to highlight the specific situation of acoustic consultants and practitioners, who do not necessarily hold an engineering degree, or do not hold a recognised engineering degree. We would like to acknowledge the NSW and QLD Division, who shared their experience with registration schemes in their states, for their support.

Marc Buret

\section{SA Division}

It's been a very quiet few months here in SA due to COVID restrictions. We are hoping things can resume in the near future.

Greg Barry

\section{QLD Division}

QLD division activities have been restricted due to COVID-19. We are hoping to resume activities when restrictions have been lifted.

\section{Richard Devereux}

\section{AAS Annual General Meeting}

As we all are experiencing, 2020 is the year of adapting to changes in circumstances. The AAS AGM is usually held at the time of the annual conference in November which is after the AGM for each of the Divisions. This year it will be held by alternative means and in early December so watch out for the notifications.

\section{IMPORTANT NOTICE}

\section{AAS general secretary email change}

As advised the AAS has experienced some technical difficulties with web servers. As a result emails may not have reached their intended recipients. If you have not received a response to an email you have sent, please email the General Secretary at the new email address : gs@acoustics.org.au to ensure your enquiry is attended to.

\section{BRÜEL \& KJJER CALIBRATION SERVICES GLOBAL EXCELLENCE, LOCAL EXPERTISE}

Thanks to factory-trained service engineers, multiple up-to-date factory calibration systems and over 40 years of experience serving Australian customers, Bruel \& Kjaer service is the partner of choice for many National and International businesses.

Bruel \& Kjaer Service provides full service, support and calibration for the complete range of Brüel \& Kjær Sound \& Vibration solutions including LDS vibration test systems.

Accredited calibration to the latest standards of:

$$
\begin{array}{ll}
\text { - Sound level meters } & \text { - Analysers (including multi-channel } \\
\text { - Calibrators } & \text { systems) } \\
\text { - Microphones } & \text { - Noise dose meters } \\
\text { - Accelerometers } & \text { - Amplifiers } \\
\text { - Vibration Meters } & \text { - Filters }
\end{array}
$$

Calibration service for non Brüel \& Kjær equipment is available, as well as rental and loan equipment on request.

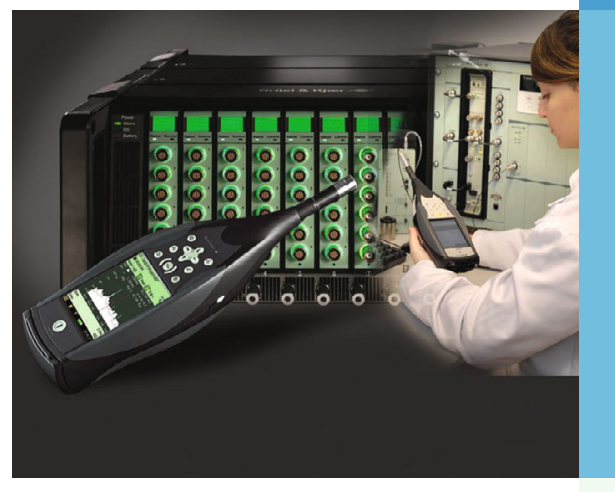

Bruel \& Kjaer Australia (HQ) Suite 2, 6-10 Talavera Road North Ryde NSW 2113

www.bksv.com auinfo@bksv.com Tel: +61298898888

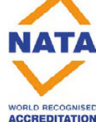

www.bksv.com/service 


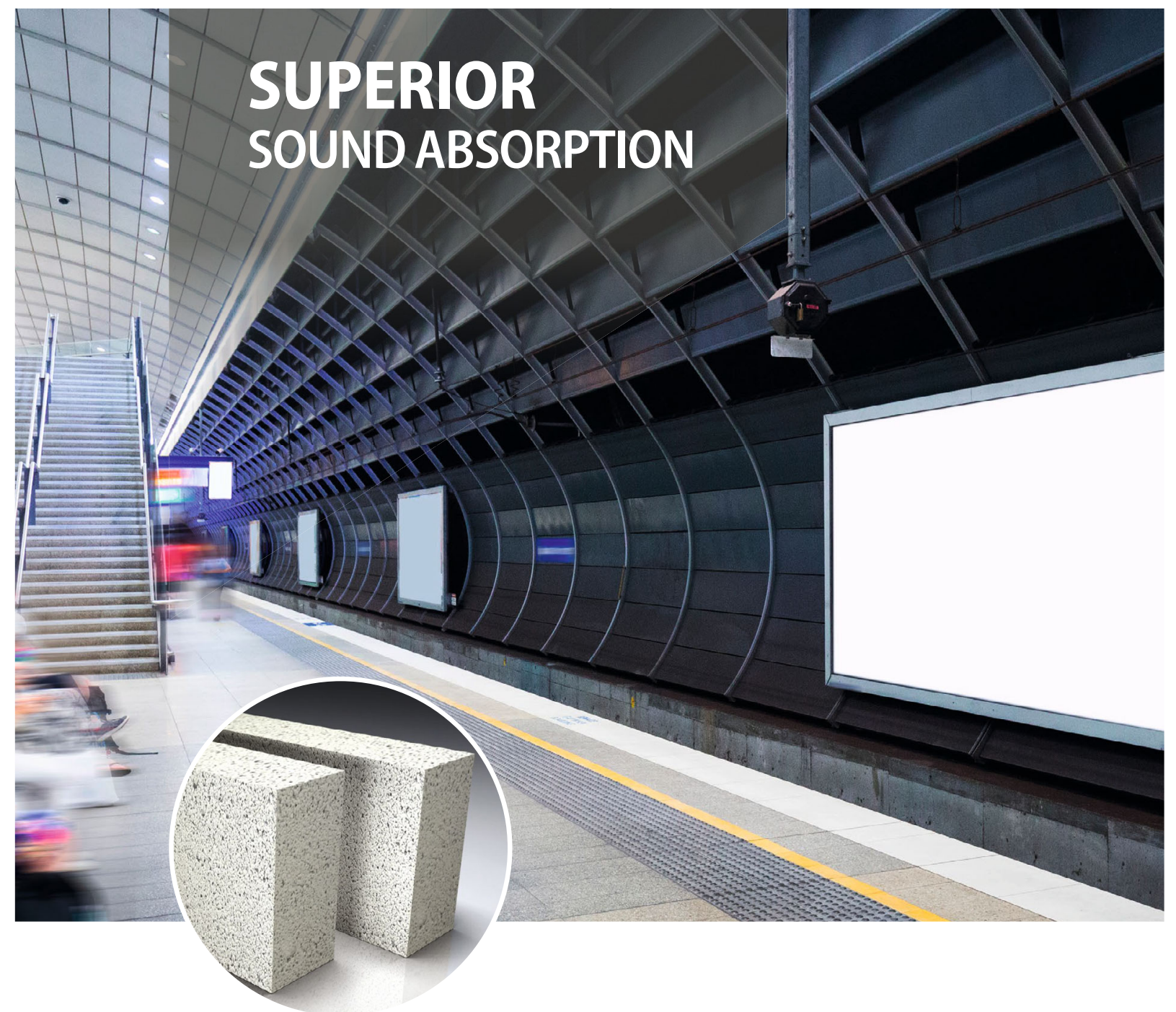

\section{REAPOR}

Reapor is a sound absorbing panel made from recycled glass granules,

suitable for a wide range of applications where effective noise reduction

is required - especially in areas with high humidity or fire concerns.

Reapor panels are non-combustible and suitable for both indoor and

outdoor applications.

Features

- Non-combustible

- NRC of 0.95 (50 mm panel)

- Fibre-free

- Rigid and durable

- Non-toxic

\section{Applications}

- Rail and motorway tunnels

- Substations and enclosures

- Exit ways, stairwells and smoking areas

- Cooling towers

- Restaurants and cafés 


\section{Acoustics News}

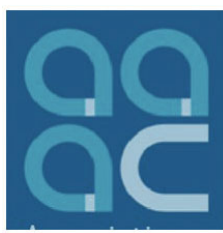

\section{AAAC (The Association for Australasian Acoustical Consultants)}

Enter the Client Choice Awards before it's too late! The category has now opened up to consulting firms of all sizes. The AAAC is continuing our partnership with Beaton, research manager of the Client Choice Awards, to co-promote the Best Acoustical Consulting Firm awards category.

We encourage AAAC members to take part. Get signed up today to start collecting as much valuablew client feedback as possible and enjoy the chance to join the list of Client Choice Awards winners. The cost of entry is only $\$ 150$. Find out more on the website :- https://clientchoiceawards.net.

Richard Haydon

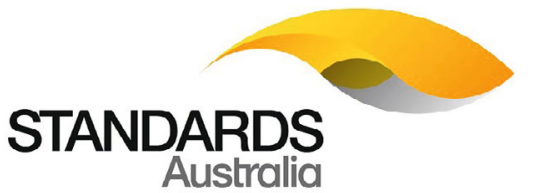

\section{Definitions from $A$ to Z: National Dictionary of Building \& Plumbing Terms}

With the aim of providing clarity and consistency to the building and plumbing industry, Standards Australia, in partnership with the Australian Building Codes Board (ABCB) has launched the National Dictionary of Building and Plumbing Terms. http:// www.constructiondictionary.com.au/

Individuals (government, industry and consumers) will be able to search for terms and definitions in the NCC, Australian (and joint AS/NZS) Standards, and Handbook 50:2004 Glossary of Building Terms.

\section{Public comment}

This is of particular interest to any who have tried to comment during the public review process for Australian Standards.

Standards Australia has advised that "To make public commenting easier and simpler for both commenters and committees" a new public commenting platform which aims to improve and automate the public comment and resolution process by making it more open, transparent and interactive has been launched. (from Editor ....let's hope this lives up to the claim!!).

\section{World Standards Day}

On Wednesday, 14 October Standards Australia and standards organisations across the globe celebrated World Standards Day 2020 by acknowledging the collaborative efforts of experts, committee members and organisations worldwide for their continued contribution to the development of standards. This year's theme, 'protecting the world with standards' provides an important reminder of the role standards can play in supporting our future. You may not know it, but standards are heroic in reducing our impact on the planet. Take a look at Standards Australia's World Standards Day video to gain an insight and learn more about how standards help to protect our planet.

\section{a न्g.8 Hearing Hub}

National Acoustic Laboratories (NAL) launched the Soundbites webinar platform in May 2020. This initiative was created to share NAL's world leading research and connect with the national and international hearing health community during these COVID-19 'isolated' times, and beyond. In three months, NAL hosted 15 Soundbites webinars and engaged professionals and organisations all over the world. There were over 800 attendees from 26 countries and over 1,500 views of Soundbites on YouTube.

The Soundbites series explored current and emerging hot topics in Audiology, including adult rehabilitation, telehealth or connected hearing health deep dive from various perspectives, hearing loss prevention, empowerment, LOCHI, realistic listening environments, over-the-counter devices and behavioural insights on device choices made by clients.

Follow their Events page for upcoming webinars. Recordings of past presentations can be found on the NAL YouTube channel. If you would like to co-host a webinar or explore collaboration opportunities with NAL, contact them at:Soundbites@nal.gov.au.

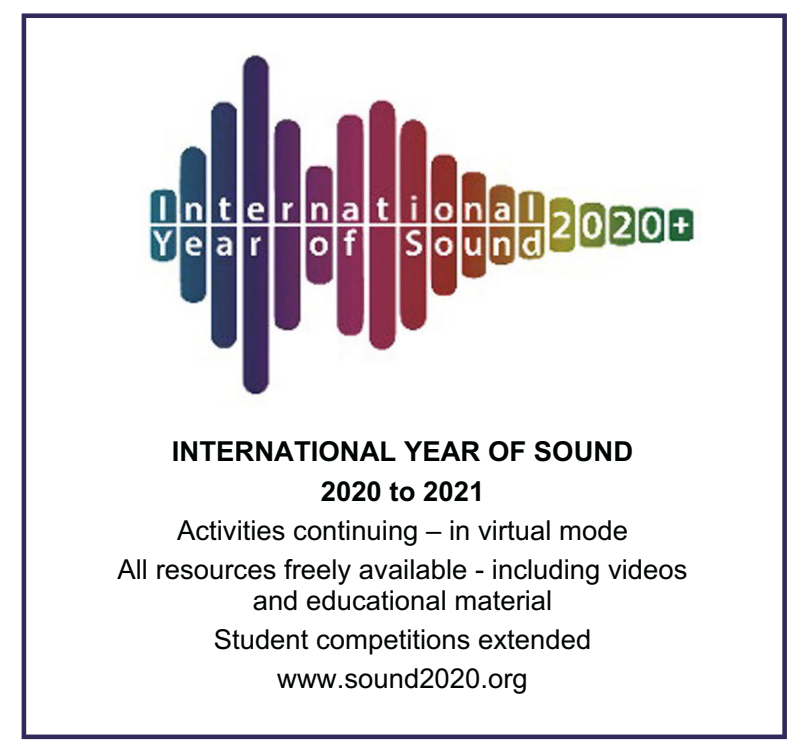


LOOKING TO TEST PRODUCT NOISE LEVELS WITH CONFIDENCE AND CONTROL?

\section{JOB DONE.}

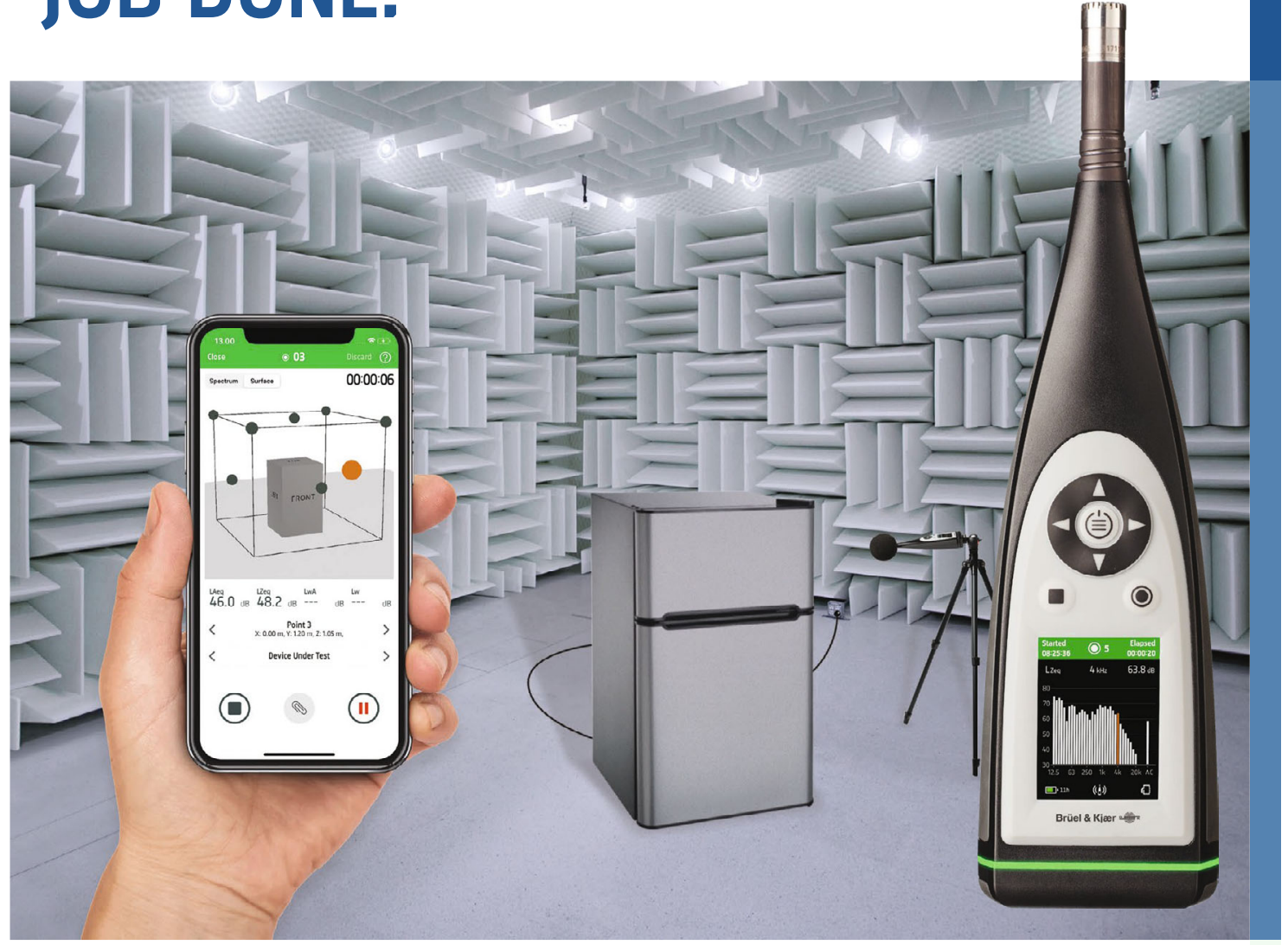

Whether it is for compliance or quality assurance, when it comes to product noise testing, it is essential to have a sound level meter that gets your job done first time, every time and without hassle. The new B\&K 2245 Product Noise gives you absolute confidence and control through user-friendly mobile apps and functionality tailored for your task, including test process guidance, wireless data transfer, instant analysis and results, smart data handling on your PC, and more.

B\&K 2245 is type approved by PTB.

To simplify your job-to-do, visit www.bksv.com/2245

\section{Brüel \& Kjær} an $\mathbf{H B K}$ company
INTRODUCING A NEW SOUND LEVEL METER DESIGNED FOR YOUR JOB.

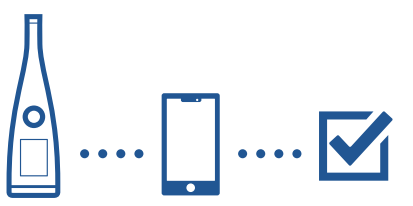

Brüel \& Kjær Australia

Telephone: +61298898888 · Fax: +6198898866

Email: auinfo@bksv.com 


\section{General Items}

\section{Scientists recreate prehistoric acoustics of Stonehenge}

Scientist have succeeded in recreating the soundscape of the inner sanctum of Stonehenge. It's the first time the acoustics of the famous temple have been accurately experienced in up 2000 years.

A research team from the University of Salford, led by Professor Trevor Cox, built a 1:12 scale model of the original structure, and then tested it in their sound laboratory. Some of the findings suggest sounds produced inside the original Stonehenge would have been less audible to anyone outside. See below for a link to the full article written by David Keys and published in 'The Independent"

Article - Prehistoric Acoustics of Stonehenge

\section{How hackers can pick your locks - Just by Listening}

Researchers at the University of Singapore have discovered that it's possible for hackers to "pick locks" based on the sounds a key makes when it is inserted and turned inside the lock.

In an attack they've named "SpiKey" the researchers described how by using a smartphone to record the metallic clicking sounds when a key is used in a lock, hackers can then produce the means to pick the lock. Simply they record the sounds then use software to convert the sounds to match up with key ridges and then create a 3D printed model of the key.

See below for a link to the full article written by Courtney Linder Article - how hackers can pick your locks - just by listening

\section{Singing, aerosols and Covid-19}

During 2020 many social activities have been closed down for varying periods due to the risk for the spread of Covid 19. Group singing has been one of these activities. Con Doolan and his team at UNSW, Sydney have studied the distribution of aerosols created by singing using tools and techniques adapted from their work on aeroacoustics and wind farm noise. They took high-speed videos of a person singing a major scale, as do-re-mi-fa-so-la-ti-do, and then tracked the emissions of droplets and aerosols. They found certain notes, such as "do" and "fa", generated more aerosols than others and that the direction of emissions changed with different consonants. Their findings contributed to the growing body of research looking at the transmission risk for group singing and the role of aerosols. This information then fed into the development of guidelines on how those wishing to sing together in person, and not on zoom, could do so with less risk. These guidelines then allow for the gradual return of important social and cultural activities for our society. For more information and the videos see https:// theconversation.com/this-video-shows-just-how-easily-covid19-could-spread-when-people-sing-together-144789

\section{B\&K Online training}

Brüel \& Kjær offer a comprehensive range of online training that covers theory, applications and instrumentation. It is tailored for engineers, technicians, and designers new to the field of sound and vibration, as well as seasoned specialists. Along with the tailored training, Brüel \& Kjær offer webinars which are free of charge which can be watched live or access to a recorded be requested via email, auinfo@bksv.com To see the currently available webinars follow the link to "Webinars" from this page https://www.bksv.com/en/Training. Also available for immediate viewing from the link on the same page to "HBK Expert Talk" are talks covering topics including Strain Gauge Measurements, Getting Measurements off the Ground, Calibration, Sample Rate and Filter, Finding the Right Accelerometer and Common Mode Rejection.

\section{PRODUCT SPOTLIGHT}

\section{How loud is a camera shutter?}

The team at B\&K measured Camera shutter noise with the B\&K 2245 Class 1 Sound Level Meter equipped with their mobile Enviro Noise Partner App - see what they found in video in the link below

\section{B\&K Knowledge Centre - Camera Shutter}

Camera noise is just one of the many things you can measure with a B\&K 2245 Sound Level Meter. B\&K 2245 Sound Level Meter is available in 4 versions, each designed with specific features for measuring and controlling exhaust noise, environmental noise or workplace noise, or for supporting a more general measuring need.

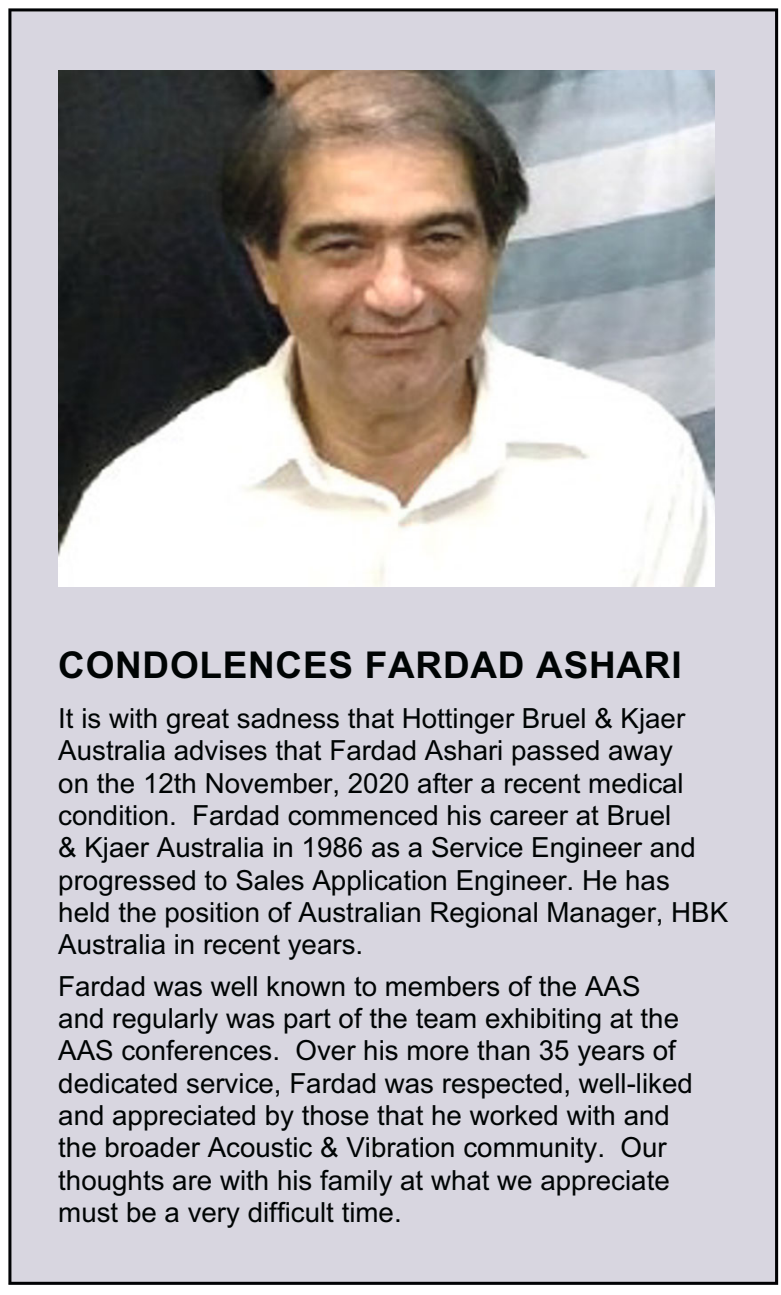




\section{HOWARD POLLARD}
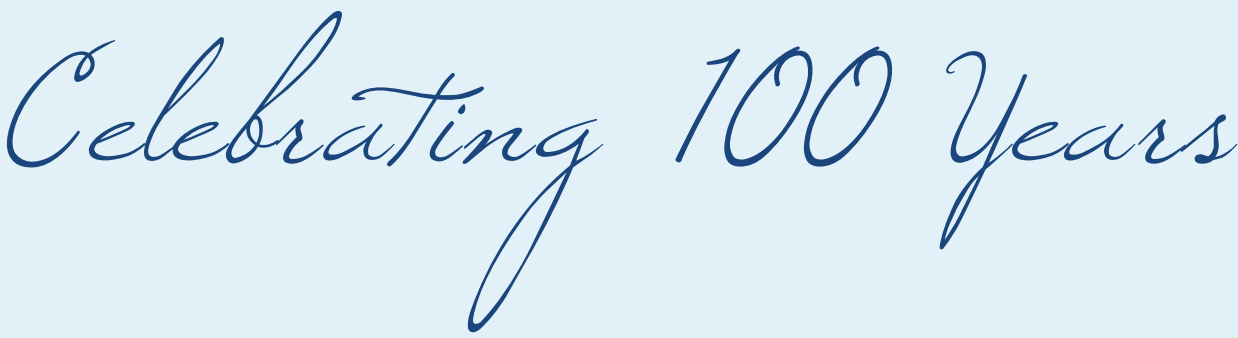

Howard Pollard had a lovely day celebrating his 100 th Birthday on September 2 nd. He received many messages, phone calls and gifts. In particular he was very honoured to receive letters from the Queen, the Governor General and the Prime Minister congratulating him on reaching such an amazing milestone.

Acoustics Australia and the AAS sent Howard a special box of almost 100 handmade chocolates to mark the occasion. He was very surprised, but also very grateful when he received his gift.

The August issue featured an item on Howard's achievements and contributions to the Australian Acoustical Society and in particular his editorialship of this journal.
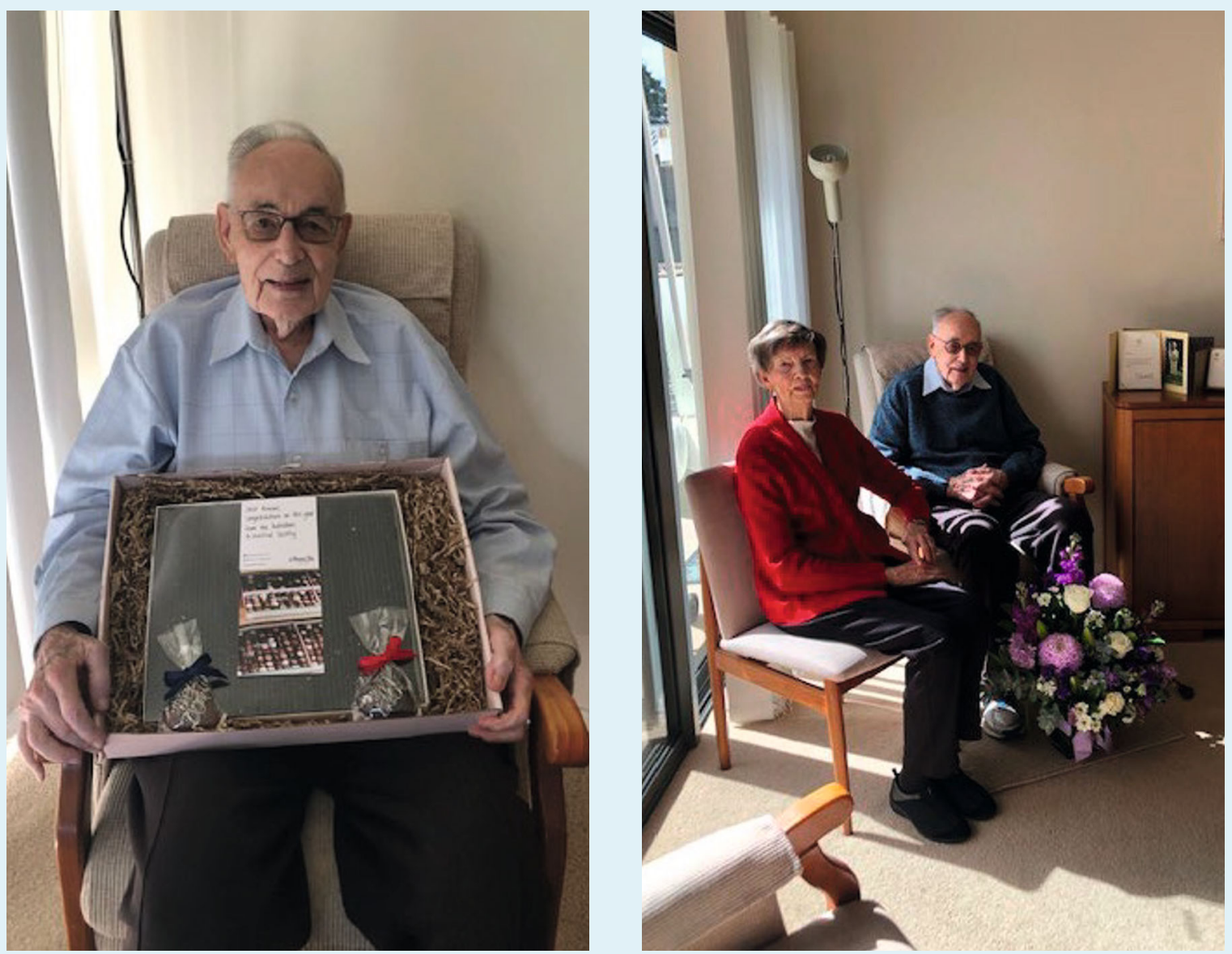


\section{BOOK REVIEW}

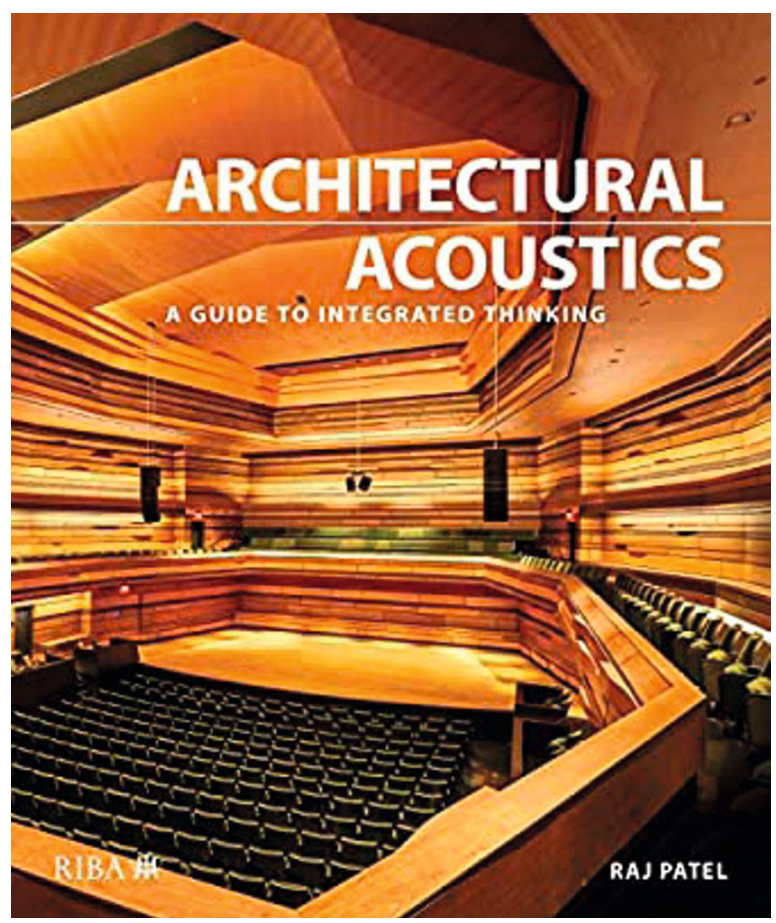

\section{Architectural Acoustics: A Guide to Integrated Thinking}

\author{
Author: Raj Patel \\ ISBN: 9781859466360 (hardback), 9780429348044 (eBook) \\ Published by RIBA Publishing, 2020
}

This book presents the topic of architectural acoustics through numerous case studies, most of which reflect commercial work by the multidisciplinary international consulting firm Arup. The case studies cover a very wide range of application areas in multiple countries, with diverse acoustic requirements. Hence it presents a diverse overview of the scope of architectural acoustics from a professional perspective.

Architectural Acoustics begins with some broad introductory chapters that serve to orient the reader in ways of thinking about sound and architectural acoustics. The chapters 'Acoustics and Architecture', 'Soundscapes', 'Sound and Architecture - The Future?', and 'I and We in Acoustics' (by Craig Dykers) present brief position statements, drawing on contemporary trends and developments in architectural acoustics and its contributions to personal experience, the professions and more generally in society. The chapter 'Acoustic Terminology' lightly sketches some technical concepts that pertain to various subfields of architectural acoustics, with sections on basic physics, psychoacoustics, environmental acoustics, room acoustics, sound insulation, mechanical and electrical systems, and sustainability. The chapter seems to be aiming to make the book (and acoustics more generally) accessible to readers who are untrained in acoustics.

The main part of the book is the case studies. These are organized over 24 topics contributed by different authors but in a consistent style. Each topic is introduced by an overview of key issues that should be considered in design (entitled 'What's important and why', presented as a 1-page table explaining prioritized issues) along with a section on 'historical context'. The latter heading does not quite fit the content of many of these unreferenced sections, which instead present general commentary on the challenges and opportunities of their respective topic. The topics are Arenas, Stadia, Concert Halls, Theatres, Opera, Dance, Multi-use Halls, Amplified Sound, Immersive Spaces, Health and Wellness, Workplace, Education, Civic and Courthouses, Hotels and Residential, Labs and Research, Libraries, Cinema, Museums and Galleries, Recording and Broadcast, Restaurants, Retail, Aviation, Rail and Worship. Cases studies are generally presented as textual descriptions accompanied by one or more photographs, highlights of details, and sometimes diagrams or visualizations of acoustic simulations. The book is richly illustrated, with more space devoted to figures than to text. Case studies include some Australian ones such as Elizabeth Murdoch Hall (Melbourne) and St Mary's Cathedral (Sydney), and include contributions by Arup's Australian teams.

The strength of the book is the sheer diversity of case studies. The book paints a picture of architectural acoustics practice that goes far beyond the frequently published topics of auditoria, studios or sound insulation in buildings. The case studies are presented as examples, avoiding technical acoustics criteria or data, and so are set up to invite conversation between disciplines. This is reflected by the book's subtitle (A guide to integrated thinking).

The practice of architectural acoustics is often invisible, sometimes forgotten, but is an essential requirement for high quality indoor environments such as those covered in this book. In this respect, one of the book's important contributions is to show something of acoustics to people from other disciplines and professions. In one sense, the book is not for acousticians, but nevertheless an acoustician could find it useful in communicating with others or in thinking broadly about the field. It celebrates significant international achievements by one of the major consulting practices in architectural acoustics, showing how high-quality acoustic design can improve the human environment.

\section{Densil Cabrera}

Sydney School of Architecture, Design and Planning, The University of Sydney

Densil Cabrera is an Associate Professor in audio and acoustics. His research focuses on architectural acoustics, including the acoustics of open-plan offices and auditoria, spatial control of sound reflections, and aspects of voice and hearing. He directs the audio and acoustics specialization in the Master of Architectural Science at The University of Sydney. 


\section{FUTURE CONFERENCES}

Editorial Note: Under the extraordinary world we are living in at the time this goes to press there is great uncertainty regarding future meetings nationally and internationally. Some meeting organisers have bravely advised postponed dates, others have converted to e-conferences and others are yet to confirm if the meeting will go ahead. Acoustics Australia take no responsibility for the accuracy of the listings below and recommends that you seek the latest details from the news flashes on the respective web pages for the conference website.

Additional meetings may be listed on the ICA calendar at:- http://www.icacommission.org/calendar.html

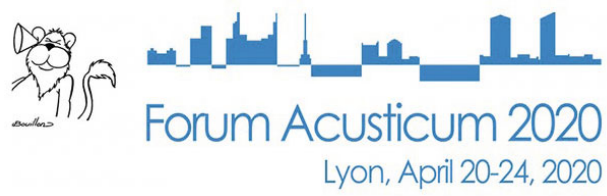

\section{Forum Acusticum - Lyon}

Date change - 7-11 December, 2020 e-conference

The European Acoustical Association together with the French Acoustical Society is pleased to invite you to the 9th Forum Acusticum to be held as an e-forum. The forum will address all topics of Acoustics, from physical acoustics to sound perception (of humans and animals), including industrial applications of acoustics. An e-exhibition will also be available.

https://fa2020.universite-Iyon.fr/

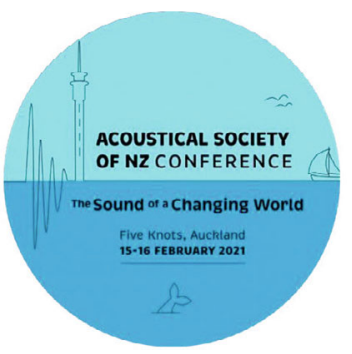

\section{ASNZ Conference 2021, Auckland, New Zealand}

\section{5-16 February 2021}

The Acoustical Society of New Zealand is holding is biennial conference in Auckland on the 15th and 16th of February 2021. The conference will be held at the Tamaki Yacht club - overlooking the beautiful Hauraki gulf. The conference programme will include technical presentations from scientists, engineers and researchers, several keynote talks and a trade exhibition area. Abstracts for presentations and papers are currently being sought. To submit an abstract, register for the conference, or for other general information, please visit the conference website: https://www. acoustics.org.nz/conferences/asnz-conference-2021.

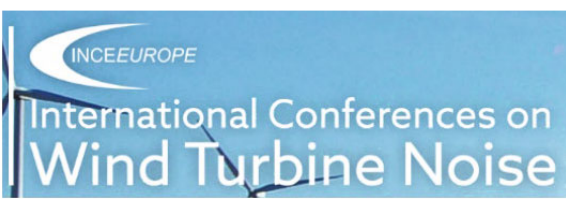

\section{WTN2021 - Ninth Int conf on Wind Turbine Noise}

18-19 May 2021

e-conference

These biennial conferences were instigated by Geoff Leventhall for INCE Europe in 2005. For our ninth conference we we will be hosting as an e-conference in Europe in Europe in May, 2021.

The conferences have become the main international forum for the technical discussion of wind turbine noise from how it is generated to its effect on neighbours. They aim to bring together the latest information on noise and vibration from wind turbines and attract delegates from a wide range of disciplines - aeroacoustic research students, researchers into the effects of noise on people, acoustic consultants and representatives of central and local government.

They provide a venue for researchers on wind turbine noise and its effects on people to meet together and also to meet with those who design wind turbine installations, both in industry and in the planning process.

Wind Turbine Noise 2021 will be different from previous conferences because it is an e-conference. As such we shall be emphasising discussions, conversations and other formats that get people together.

https://www.windturbinenoise.eu//

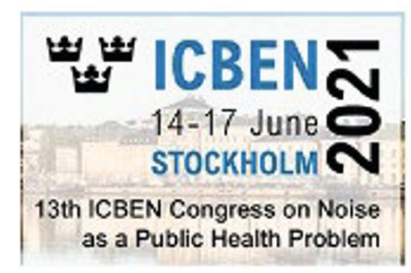

ICBEN 2021 - Stockholm

Date Change - 14-17 June 2021

The 13th ICBEN Congress on Noise as a Public Health Problem, originally scheduled as ICBEN 2020, will now been known as ICBEN 2021 and will be held June 14-17, 2021.

https://www.icben2020.se/ 


\section{euronoise 2021 \\ 21-23 June \\ Madeira, Portugal}

\section{EURONOISE 2021}

\section{1-23 June 2021}

The EuroNoise 2021 Congress will take place between 21st and 23rd of June, 2021, in the beautiful island of Madeira, a wellrecognized international touristic destination. EuroNoise 2021 will be organized by the Portuguese Acoustical Society (SPA), on behalf of the European Acoustical Association (EAA).

The technical program of this Congress will cover the main topics of acoustics, including the classical themes and the most recently developed areas. A technical exhibition will be held during the Congress days, in a place with easy access and visibility for the attendees and other interested people who would like to make short visits to exhibitor's booths.

http://www.spacustica.pt/euronoise2021/

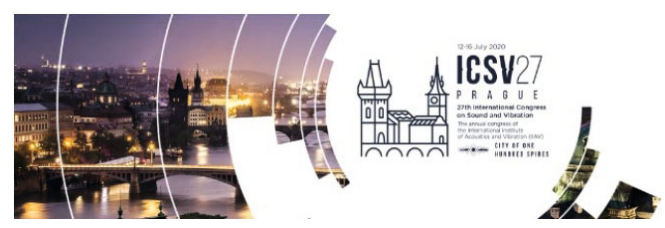

\section{ICSV27 - Prague}

Date Change - 11-15 before July 2021

Due to the situation with COVID-19 a decision was made to postpone the ICSV27 congress at the Hilton Prague hotel by 12 months to July 2021.

This annual IIAV congress is a leading event in the area of acoustics and vibration and provides an important opportunity for scientists and engineers to share their latest research results and exchange ideas on theories, technologies and applications in these fields. https://icsv27.org/

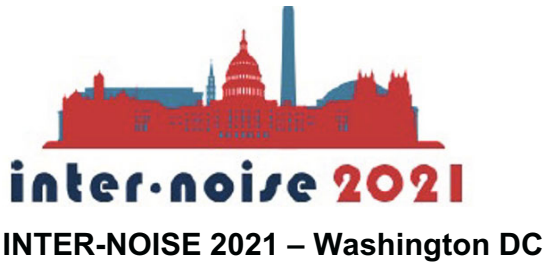

On behalf of the INTER-NOISE 2021 Congress organization, we wish to invite you to attend the 50th International Congress and Exposition on Noise Control Engineering that will be held in Washington, DC, USA on 1-4 August 2021. We now planning for a virtual or hybrid mode depending on the COVID-19 conditions and travel restrictions.

The Congress is organized by the Institute of Noise Control Engineering of the USA (INCE-USA) and Pro Acustica (Brazil), on behalf of the International Institute of Noise Control Engineering (I-INCE). The Congress theme is "Next 50 Years of Noise Control" and the program will cover aspects of noise control engineering, acoustics and vibration. Special sessions or events will be held on the 50th INTER-NOISE congress and on other relevant topics. https://internoise2021.org/

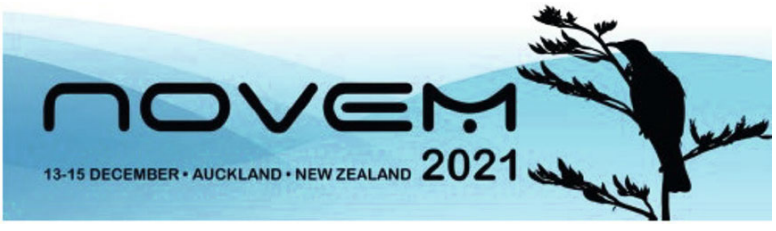

\section{NOVEM 2021}

Date Change - 13-15 December 2021

NOVEM 2021 is the 7th in the series of NOVEM conferences. NOVEM 2021 has been postponed due to COVID-19 and will now be held 13-15 December 2021 in the beautiful city of Auckland, New Zealand at the Owen G Building, The University of Auckland. The conference will be a major gathering of researchers, from research establishments and from industry, working in the areas of noise and vibration.

The emphasis of the conference is on new and emerging methods, techniques and technologies in acoustics and vibration.

As with previous NOVEMs, each day will contain a Keynote Forum, which will bring together key specialists within a common theme, followed by extensive discussion. These themes represent major scientific challenges related to noise and vibration.

https://www.novem2021.ac.nz/

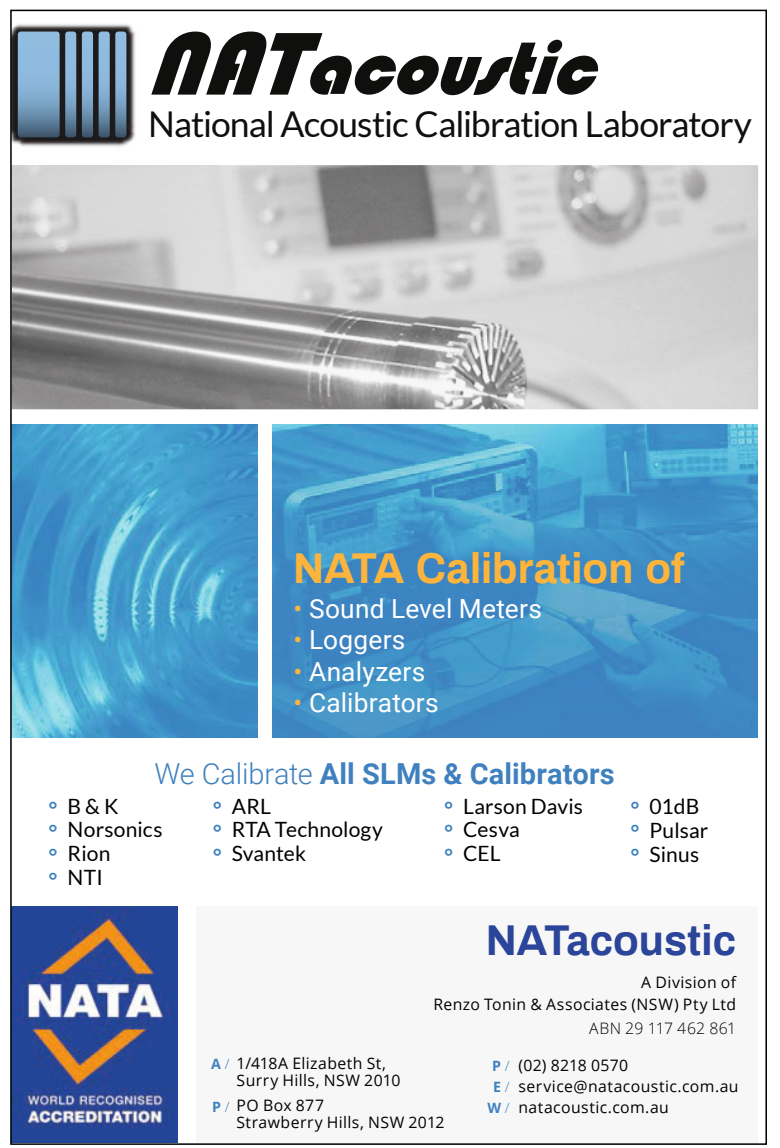




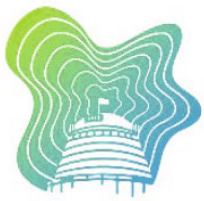

\section{ACOUSTICS 2022 \\ THE NATURE OF ACOUSTICS \\ 31 OCT -2 NOV 2022 \\ TE PAPA, WELLINGTON, NEW ZEALAND}

\section{Acoustics 2022, Wellington}

Date Change - 31 October-2 November 2022

The Acoustical Society of New Zealand (ASNZ) and Australian Acoustical Society (AAS) Joint Conference will be held at Te Papa Tongarewa Museum in Wellington New Zealand, from 31October-2 November 2022.

Acoustics 2022 will provide a unique opportunity for manufacturers and suppliers to showcase the latest developments in acoustic instrumentation, software and noise and vibration control products.?

Surrounded by nature and fuelled by creative energy, Wellington is a compact city with a powerful mix of culture, history, nature and cuisine. Fuel your visit with strong coffee and world-class craft beer - Wellingtonians are masters of casual dining, with plenty of great restaurants, night markets and food trucks.?

On the waterfront itself you'll find Te Papa Tongarewa Museum, New Zealand's national museum. Te Papa, as it's colloquially known, means 'our place' and is one of the best interactive museums in the world.

It is an iconic New Zealand building, right in the heart of the capital city. It is easily accessible by international and domestic flights into Wellington airport, which is only a short 15 min drive from the venue.

On behalf of the Acoustics 2022 Organising Committee, we look forward to welcoming you to Wellington in November and hope that the conference gives you an opportunity to strengthen your existing networks and that you leave with great memories, fresh ideas, and new friendships.

We encourage you to save the dates in your calendar and register your expression of interest today to be kept up to date with the latest information and program news.

https://www.acoustics2022.com/

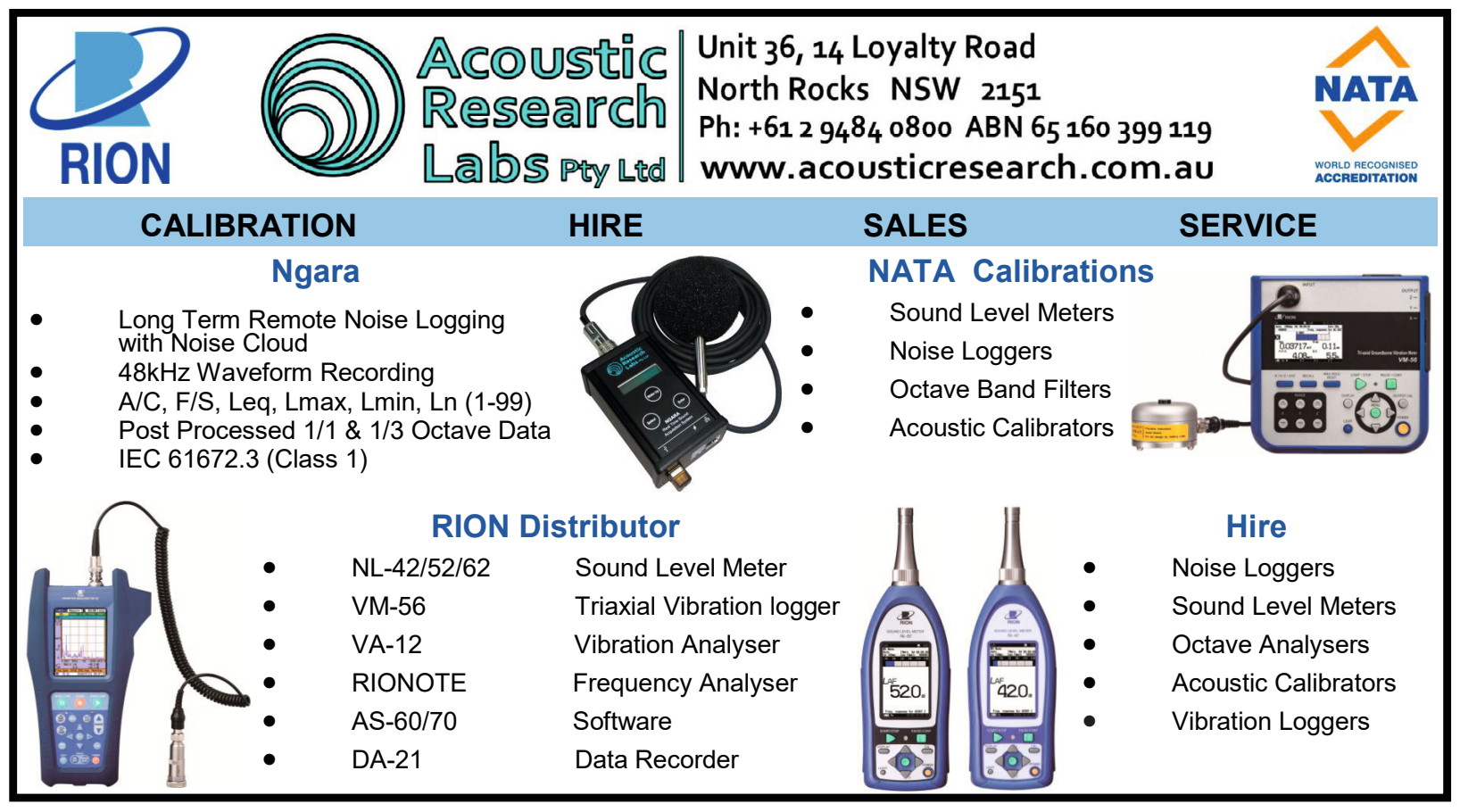




\section{SUSTAINING MEMBERS}

The following are Sustaining Members of the Australian Acoustical Society.

Full contact details are available from www.acoustics.org.au or click on company logo.

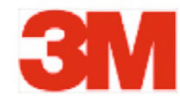

3M AUSTRALIA

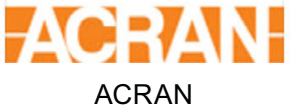

AERIS $2 \mathrm{~N}$

Aerison Pty Ltd

\section{Broadcrest}

Broadcrest Consulting

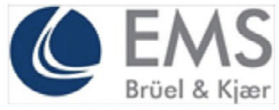

EMS Bruel \& Kjaer

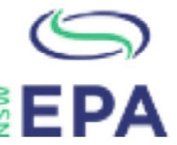

NSW Environment Protection Authority

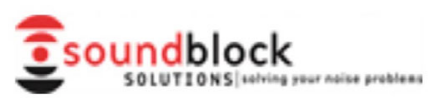

Soundblock Solutions Pty Ltd

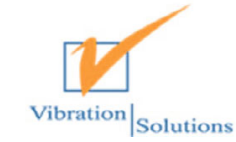

Vibration Solutions

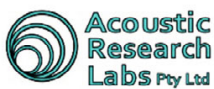

Acoustic Research Labs Pty Ltd

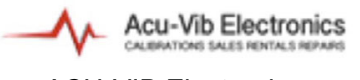

ACU-VIB Electronics

\section{Armstrong \\ ELING \& WALL SOUUTIONS}

Armstrong Ceiling Solutions

(Australia) Pty Ltd

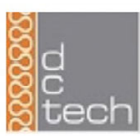

Dynamic Composite Technologies

\section{Brüel \& Kjær n \\ an HBK company \\ Hottinger Bruel \& Kjaer Australia Pty Ltd \\ Pyrolek.}

Pyrotek Noise Control

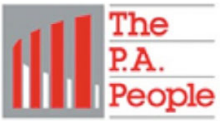

The P.A. People Pty Ltd

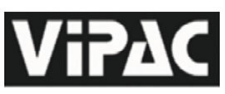

Vipac Engineers \& Scientists Ltd

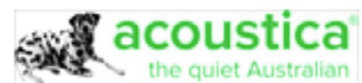

Acoustica

Adamsson

Engineering

Adamsson Engineering P/L

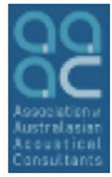

Association of Australasian Acoustical Consultants

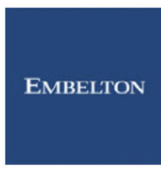

Embelton

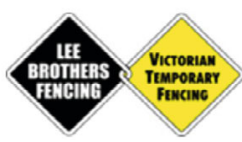

Lee Brothers Fencing Group

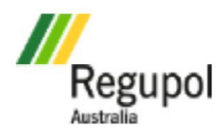

Regupol (Australia) Pty Ltd

\section{USG BORAL}

USG Boral 


\section{DIARY}

Editorial Note - Under the extraordinary world we are living in at the time this goes to press there is great uncertainty regarding future meetings nationally and internationally. Some meeting organisers have bravely advised postponed dates, others have converted to e-conferences and others are yet to confirm if the meeting will go ahead. Acoustics Australia take no responsibility for the accuracy of the listings below and recommends that you seek the latest details from the news flashes on the respective web pages for the conference website.

Additional meetings may be listed on the ICA calendar at

http://www.icacommission.org/calendar.html

\section{0}

\section{7-11 December, Lyon, France}

Forum Acusticum 2020

e-conference

fa2020.universite-lyon.fr

7-11 December, USA

179th Meeting of the ASA

e-conference

www.acousticalsociety.org

\section{1}

15-16 Feb, Auckland, New Zealand

ASNZ Conference 2021

https://www.acoustics.org.nz/conferences/asnz-

conference-2021

\section{8-21 May 2021, Europe}

WTN2021 - Ninth Int conf on Wind Turbine Noise

e-conference

https://www.windturbinenoise.eu//

\section{7-11 June, Seattle, Washington}

180th Meeting of the Acoustical Society of America www.acousticalsociety.org

\section{4-17 June, Stockholm, Sweden}

13th ICBEN Congress on Noise as a Public Health

Problem

www.icben2020.se

\section{1-23 June, Madeira, Portugal}

EURONOISE 2021

www.spacustica.pt/euronoise2021/

11-15 July, Prague

28th International Congress on Sound and Vibration (ICSV28) https://icsv27.org/

\author{
1-4 August, Washington, USA \\ INTER-NOISE 2021 \\ Hybrid conference \\ www.i-ince.org/
}

13-15 December, Auckland, New Zealand

NOVEM 2021 Noise and Vibration Emerging Methods https://www.novem2021.ac.nzl

\section{2}

\section{3-27 May, Denver, Colorado}

182nd Meeting of the Acoustical Society of America www.acousticalsociety.org

\section{4-28 October, Gyeongju, Korea}

ICA 2022 http://www.icacommission.org/calendar.html

31 October-2 November, Wellington, New Zealand Acoustics 2022

https://www.acoustics2022.com/

\section{3}

\section{4-8 December, Sydney, Australia}

Acoustics 2023 Sydney

Joint meeting ASA, AAS, WESPAC, PRUAC acoustics2023sydney@arinex.com.au
Meeting dates can change so please ensure you check the conference website and also check ICA calendar at http://www.icacommission.org/calendar.html 